\title{
ESTABILIDAD DE LOS DOCENTES CURRICULARES DE INSTITUTOS PRIVADOS RECONOCIDOS O ADSCRIPTOS A LA ENSEÑANZA OFICIAL: EN TIEMPOS DE NORMALIDAD Y EN EL DE LA PANDEMIA
}

\section{STABILITY OF CURRICULAR TEACHERS OF RECOGNIZED PRIVATE INSTITUTES OR ASSIGNED TO OFFICIAL EDUCATION: IN TIMES OF NORMALITY AND IN TIMES OFTHE PANDEMIC}

\author{
Ricardo Francisco Seco ${ }^{1}$
}

RESUMEN:

En tiempo de pandemia, el DNU N³29/2020(B.O.,31/3/2020) del Poder Ejecutivo nacional se dictó en el marco de la emergencia sanitaria por el coronavirus y sus prórrogas decididas por el DNU N487/2020 (B.O.,19/5/2020) y el DNU N624/2020 (B.O.,29/7/2020) prohibieron los despidos sin justa causa y por causas económicas y por fuerza mayor por el plazo de 60 días contados a partir de la fecha de su publicación en el Boletín Oficial, desde el 31 de marzo hasta el 29 de mayo de 2020, luego hasta el 28 de julio y más tarde hasta el 26 de setiembre de 2020. Se ha establecido un régimen de estabilidad propia o absoluta para todos los trabajadores privados a los que alcanzan esos DNU, incluidos los docentes privados de cualquier nivel, curriculares o no- pero pro tempore, porque es limitada al plazo de veda. La decisión del Poder Ejecutivo Nacional aparece como constitucional y convencional, adecuada a normas supra legales que él mismo cita y a otras ut supra referidas, como a la jurisprudencia de la CSJN y la CIDH. Pasada la emergencia y la vigencia del DNU, la incógnita está en si se volverá para todos los trabajadores privados en Argentina al sistema de estabilidad relativa impropia o se podrá pasara una intermedia,

1 Abogado y notario (UCC), Doctor en Derecho y Ciencias Sociales(UNC), profesor de DTySS en la UCC y en la UBP y de posgrado en DT en varías universidades argentinas y una extranjera, publicista, Presidente de la Sala de Derecho Laboral y Procesal Laboral del Instituto de Investigaciones Jurídicas de la Universidad Blas Pascal e investigador de dicha universidad, exvocal de la Cám.Civ..Com.,Trab, y Flía.,Cruz del Eje, 
como es la que acompaña a los docentes privados mencionados desde 1947, parecida a la del Estatuto de los Trabajadores español para el caso de despido improcedente, o la excepción del DNU se volverá regla.

\begin{abstract}
In times of pandemic, DNU No. 329/2020 (BO, 3/31/2020) of the national Executive Power was issued within the ffamework of the health emergency caused by the coronavirus and its extensions decided by DNU No. 487/2020 (BO, 19 / 5/2020) and DNU No. 624/2020 (BO, $7 / 29 / 2020$ ) prohibited dismissals without just cause and for economic reasons and forcé majeure for a period of 60 days from the date of its publication in the Official Gazette, from March 31 to May 29, 2020, then until July 28 and later until September 26, 2020. A regime of own or absolute stability has been established for all prívate workers to those who reach these DNU, induding prívate teachers of any level, curricular or not - but pro tempore, because it is limited to the dosed period. The decisión of the National Executive Power appears as constitutional and conventional, adequate to supra-legal norms that it dtes itsdf and to other supra-referred ones, such as the jurisprudence of the CSJN and the IACHR. After the emergency and the validity of the DNU, the question is whether it wdl return for all private workers in Argentina to the system of improper relative stability or it will be possible to move to an intermedíate one, such as the one that accompanies the prívate teachers mentioned since 1947, similar to that of the Spanish Workers' Statute in the case of unfair dismissal, or the exception of the DNU will become the rule.
\end{abstract}

PALABRAS CAVE: Covid-19, docentes privados, despido, estabilidad.

KEY WORDS: Covid-19, prívate teachers, dismissal, stability.

\title{
I. Introducción
}

1.-La estabilidad es una de las principales diferencias que existen entre los docentes dependientes de institutos educativos públicos de gestión estatal, por una parte, con los docentes curriculares de institutos de gestión privada reconocidos o adscriptos a la enseñanza oficial(de los niveles inicial, primario, secundario y terciario no universitario), con los extracurriculares de esos institutos, con los de las escuelas libres o academias o institutos privados de enseñanza y con los docentes universitarios dependientes de universidades privadas. ${ }^{2}$

La generalidad de la doctrina interpreta que los docentes dependientes de institutos privados adscriptos, de planta funcional o curriculares o programáticos, gozan de estabilidad relativa propia, arts.13 y 14, ley $13.047 .^{3}$

En cambio, los extracurriculares de esos institutos y los de las escuelas libres o academias o institutos privados de enseñanza, además de los dependientes de universidades privadas, tienen estabilidad relativa impropia.

Ello era así en épocas normales hasta ahora.

\footnotetext{
2 SECO, Ricardo Francisco en AA.W., Docentes privados. Régimen laboral, SECO, Ricardo Francisco (director), GARCÍA BRAVO, María Eugenia(coordinadora), Advocatus, Córdoba, 2019,ps.131 y sgtes y 672 y sgtes. Ver SECO, Ricardo Francisco, "El contrato de trabajo docente en universidades privadas", en AA.W, Régimen laboral de los docentes de las universidades privadas argentinas, Advocatus, Córdoba, 2012, p.101.

3 En contra SEDOFF, Miguel, Régimen jurídico de las Instituciones educativas de gestión privada, Homo Sapiens, Rosario, 2014, p.341, quien entiende que finamente la estabilidad de los docentes privados curriculares es impropia porque la garantía de la estabilidad es una indemnización.
} 
2.

- El 31 de marzo de 2020 el Poder Ejecutivo Nacional dictó el decreto de necesidad y urgencia $\mathrm{N}^{\circ} 329 / 2020$ en el marco de la emergencia por el coronavirus. El art. $2^{\circ}$ de ese instrumento dice: "Prohíbense los despidos sin justa causa y por las causales de falta o disminución de trabajo y fuerza mayor por el plazo de sesenta (60) días contados a partir de la fecha de publicación del presente decreto en el Boletín Oficial."

Durante estos 60 días- que fenecieron el 29 de mayo de 2020- estaría vigente un régimen de estabilidad propia o absoluta para todos los trabajadores privados en Argentina, incluidos los docentes privados de cualquier nivel, sean curriculares o no.

El DNU N487/2020 (B.O.,19/5/2020) dispuso la prórroga de la prohibición de efectuar los despidos mencionados por el plazo de 60 días, contados a partir del vencimiento del plazo establecido por el $\mathrm{DNU} \mathrm{N}^{\circ} 329 / 20$, como también la consecuencia nulificatoria de su contradicción.

Similar resolución se dispuso por medio del decreto 624/2020 (B.0.,29/7/2020), por el plazo de 60 días, contados a partir del vencimiento del plazo establecido por el DNU $\mathrm{N}^{\circ} 487 / 20$, aunque con algunas nuevas precisiones.

3.

-Compararemos la protección ante el despido directo causado o no que tienen solamente los docentes de institutos privados reconocidos o adscriptos de planta funcional o curriculares adscriptos a la enseñanza oficial (de los niveles inicial, primario, secundario y terciario no universitario), en época normal y en época de excepción.

\section{II.-La estabilidad relativa propia}

1.-Se ha definido a la estabilidad como "el derecho del trabajador a la conservación de su empleo hasta que él mismo decida ponerle fin o se configure algún motivo justificado (es decir, admitido como tal por el ordenamiento jurídico) de extinción", o, dicho de otro modo, "es el derecho de aquél a no ser despedido arbitrariamente". ${ }^{4}$

El derecho a la estabilidad "garantiza al trabajador la conservación del empleo", en tanto presupone la subsistencia del vínculo contractual sancionando con distinta intensidad su resolución arbitraria. ${ }^{5}$

Estabilidad es una técnica que utiliza el derecho del trabajo "para asegurar los derechos de los trabajadores y la vigencia de la relación contractual, en tanto no se haya configurado un incumplimiento de gravedad tal que no consienta la continuidad del vínculo porque se ha desmoronado el elemento fundamental que justifica el mantenimiento de la relación: la confianza." 6

\footnotetext{
4 GUISADO, Héctor C, "Estabilidad en el empleo privado", en El derecho laboral y la Corte Suprema de Justicia de la Nación. Casos típicos, VÁZQUEZ VIALARD, Antonio - FERA, Mario (coordinadores), La Ley, Buenos Aires, 2003, p.91, con diversas citas, entre ellas de Justo López; TOSELLI, Carlos Alberto, "La estabilidad en la legislación argentina", en TOSTO, Gabriel - TOSELLI, Carlos - ARESE, César, Extinción del contrato de trabajo. Diversos supuestos, Estudios de Derecho Práctico Laboral, Nuevo Enfoque Jurídico, Córdoba, 2005, p. 41.

Ver además SECO, Ricardo Francisco, "Estabilidad de los trabajadores privados. 'De Lúea' visto desde 'Álvarez c/Cencosud', Revista de Derecho LaboralActualidad, 2011-1, Rubinzal Culzoni, Santa Fe, 2011, p.12.

5 DE LA FUENTE, Horacio A., "Estabilidad en el empleo", en Tratado de derecho del trabajo, t. 3, VÁZQUEZ VIALARD, Antonio (director), Astrea, Buenos Aires, 1982, p.563.Véase LIVELLARA, Carlos Alberto, "Principales características de la legislación argentina en materia de despido dispuesto por el empleador", TySS, 2006-1038.

6 VÁZQUEZ VIALARD, Antonio, “¿Es factible negociar, a través de un convenio de empresa o de acuerdo de partes, una cláusula de estabilidad absoluta?”, Revista de Derecho Laboral, 2000-2, Extinción del contrato de trabajo-II, Rubinzal-Culzoni, Santa Fe, 2000, p. 9.
} 
En general, la doctrina y la jurisprudencia se expiden porque distintas pueden ser las formas de protección de la estabilidad; varía el modo o forma y la eficacia con que se lo hace.

Corresponde distinguir entre permanencia (concebida como una situación de hecho, expectativa o posibilidad de conservar el puesto) y estabilidad (como derecho que garantiza esa permanencia). ${ }^{7}$

También cabe distinguir a los que consideran que estabilidad tiene variantes en su concepto y eficacia de su garantía, y a los que postulan que sólo la estabilidad absoluta o propia es verdadera estabilidad, cuando consagra la ineficacia del despido arbitrario. Éstos entienden que los demás son "medios de protección contra el despido arbitrario o reparación pecuniaria por la privación injustificada de la ocupación." La generalidad de la doctrina considera que en uno $u$ otro caso se vulnera el derecho del trabajador a la estabilidad, pero varía la reacción del ordenamiento jurídico ante ese evento. ${ }^{8}$

2. -DE LA FUENTE, según la intensidad de la protección, clasifica a la estabilidad en absoluta y relativa.

En la absoluta se niega eficacia al despido directo incausadoy se admite la reincorporación forzosa del trabajador a la empresa.

En la relativa no se garantiza la reincorporación del trabajador. Se admite la eficacia del despido. Es aquella en la cual "la violación del derecho a conservar el empleo ocasiona la ineficacia del despido garantizándose la subsistencia del vínculo contractual" ${ }^{9}$

A su vez, a la estabilidad relativa la divide en propia, cuando se niega eficacia al despido, e impropia, cuando se admite la eficacia del despido.

3. -Cuando hay estabilidad relativa propia de origen legal, la resolución injustificada de la relación laboral está prohibida. Por ello, declarada la nulidad, "el contrato genera sus consecuencias normales como si el despido no hubiera existido." Es un medio técnico de asegurar al trabajador el derecho de conservar el empleo. Es correlativo de la obligación de no despedir que la ley le impone al empleador. Cabe reinstalación y salarios caídos.

Pero en esta clase de estabilidad la decisión de reinstalar es una opción que depende exclusivamente del empleador. Si éste mantiene su decisión extintiva, deberá pagar la indemnización tarifada más los salarios caídos hasta ese momento.

4. - El art. $7^{\circ}$ de la ley 13.047 (B.O.,22/10/1947) expresa:

"El personal directivo, docente, docente auxiliar, administrativo, de maestranza y de servicio de todos los establecimientos privados de enseñanza tienen derecho: a) a la estabilidad siempre que no estuviere en condiciones de acogerse a los beneficios de la jubilación, con las excepciones que se determinan en el art. 13 de la presente ley(...)".

El contenido de la norma es inicialmente amplio.

7 DE LA FUENTE, Estabilidad en el empleo, cit.

8 ídem nota anterior.

9 Ibídem. 
Empero interpretan la doctrina y jurisprudencia que entre los docentes de institutos privados reconocidos o adscriptos sólo los de plantafuncional o curriculares o programáticos gozan de estabilidad relativa propia, arts.13 y 14 de la ley 13.047.

En virtud del "principio de la equiparación"con los docentes de escuelas de gestión estatal se encuentra tutelada su estabilidad de una mejor manera que en los trabajadores privados en general debido a la procedimentalización del despido directo, aunque no tienen la estabilidad absoluta que les garantiza a aquéllos otros el art.14 bis de la CN. Pero de alguna manera la ley les reconoce algo que un poco se le parece. ${ }^{10}$

La regulación legal se endereza a limitar las posibilidades de cesantía de esa clase de docentes por el establecimiento de causales de despido directo y procedimiento para que aquél sea válido. ${ }^{11}$

Otra opinión doctrinaria expresa que por el art.14 de la ley 13.047 que "establece claramente la posibilidad de extinguir el contrato de trabajo '... por causas distintas de las taxativamente enumeradas en el artículo anterior...' imponiendo-eso sí- las consecuencias indemnizatorias que en cada caso corresponda". ${ }^{12}$

En cambio, a diferencia de los docentes curriculares antes aludidos, los docentes de institutos privados adscriptos que se hallan fuera de la planta funcional o también llamados extraprogramáticos como asimismo los docentes de academias privadas y los docentes dependientes de universidades privadas, tienen estabilidad impropia o relativa, arts.90,91 y 245 de la LCT. ${ }^{13}$ Tienen un sistema de despido libre pero indemnizado.

La ley 13.047 contiene el derecho de los docentes a la inamovilidad en la localidad, salvo conformidad escrita del interesado.

Se entiende doctrinariamente que "esta disposición constituye una prolongación del derecho a la estabilidad, similar al derecho a la ubicación reconocido a los docentes de establecimientos oficiales. La inamovilidad reconocida no incluye la del horario de trabajo, que puede ser variado siempre que se respete el turno en que se realizó la designación." 14

\section{III.- Procedimentalización del despido directo causado. Despido incausado libre pero indemnizado. En época normal}

1 .-El art.13 de la ley 13.047, que exige la "procedimentalización del despido directo causado" del personal docente curricular o de planta funcional de los institutos

\footnotetext{
10 En contra SEDOFF, Miguel, Régimen jurídico de las Instituciones educativas de gestión privada, Homo Sapiens, Rosario, 2014, p.341, quien entiende que finamente la estabilidad de los docentes privados curriculares es impropia porque la garantía de la estabilidad es una indemnización.

11 ZUNINO, Ángel Rodolfo- FANCHIN, Luis Alberto, Régimen legal de los docentes privados, Abeledo Perrot, Buenos Aires, 2008, p.203, con cita de Torre, José $\mathrm{P}$.

12 DEL BONO, Carlos María, "Personal docente de los establecimiento de enseñanza", en AA.W., Regímenes laborales especiales, FOGLIA, Ricardo Arturo(director),KHEDAYÁN, Eugenia Patricia(coordinadora), 2a edición actualizada y ampliada, Thomson Reuters La Ley, Buenos Aires, 2014,T. II, p.292.

13 En contra FERRARO, Leonardo Pablo, "Docentes de enseñanza privada', Colección Temas de derecho laboral, Regímenes especiales de trabajo, volumen III, GARCIA VIOR, Andrea (coordinadora), Errepar, Buenos Aires, 2014,p.105, quien hace una interpretación literal y amplia de la norma y dice que la garantía de la estabilidad alcanza a los docentes de planta funcional, docentes extraprogramáticos o personal administrativo, de maestranza o servicios, siempre que realicen tareas directamente vinculadas con la enseñanza.

14 PORCEL, Nerina Andrea, "Docentes de establecimientos privados de enseñanza", en Legislación usual comentada, PIROLO, Miguel Ángel(director), La Ley, Buenos Aires, Tomo I,p.787, con cita de SILVA, Luis R., Tratado de Derecho del Trabajo, VÁZQUEZ VIALARD (director), Astrea, Buenos Aires, Tomo 6,1984, p.103.
} 
adscriptos, intensifica la protección a la estabilidad relativa" de la que gozan los trabajadores comprendidos en el estatuto". ${ }^{15}$ Ese artículo reza:

"El personal sólo podrá ser removido, sin derecho a preaviso ni indemnización, por causas de inconducta, mal desempeño de sus deberes o incapacidad física o mental, previa sustanciación del correspondiente sumario por autoridad oficial competente, en el que se garantizará la inviolabilidad de la defensa."

De ese modo la libertad del propietario del establecimiento educacional de esa clase de institutos se encuentra limitada por la existencia de causales taxativamente enumeradas de despido y supeditada la cesantía a la previa intervención y calificación por la autoridad administrativa competente. ${ }^{16}$

Esa norma ha sido reproducida, indebidamente por incompetencia legislativa, en viejas leyes provinciales. ${ }^{17}$

Las causales de despido, si bien son taxativas, a la vez son genéricas, amplias, equivaliendo a la injuria que ahora prevé el art.242 de la LCT. ${ }^{18}$

A la última causal del art.13 la consideramos como no vigente. ${ }^{19}$

2.-Al empleador, propietario del establecimiento educativo, del plexo normativo relacionado, se le abren tres posibilidades:

"a) la de no invocar causa para el distracto y, en consecuencia, tal ruptura del vínculo conllevará la obligación de pago de las indemnizaciones previstas por la LCT para este supuesto;

b) la de invocar algunas de las causales que la ley 13.047 establece como fundamentos posibles del despido"- inconducta, mal desempeño..."- debiendo en este caso acreditar la causal esgrimida en sumario administrativo por ante la autoridad de aplicación educativa provincial en las provincias o en la CABA el Consejo Gremial de la Docencia Privada, lo que, en caso de así probarse eximirá al empleador del deber de pago de las indemnizaciones de la LCT;

c) la de invocar otras razones no comprendidas en la enumeración de la ley 13.047, en cuyo caso la suficiencia de tal razón para el despido podrá ser analizada por el juez laboral a la luz de la LCT y su concepto de 'injuria laboral'". 20

Insistimos que en épocas normales se admite el despido directo sin expresión de causa a esta clase de docentes- art.14de la ley 13.047-sin necesidad de sumario previo, el que conlleva las indemnizaciones que prevé la LCT para el caso, arts.231,232, 233 y 245,LCT, con los agravamientos que corresponda.

Aclárase que desde una época "seminormal", si la comparamos con la de pandemia, rige el

\footnotetext{
15 PIROLO, Miguel Ángel, "La extinción del contrato de trabajo en las relaciones regidas por los estatutos especiales", en Revista de Derecho Laboral, Estatutos y otras actividades especiales I: "Extinción del contrato de trabajo II, Rubínzal Culzoni, Santa Fe, 2002, p. 251

16 TORRE, José Patricio, "Nota sobre la estabilidad y remuneración de los docentes privados", LT, Año XX, N 235, julio de 1972, ps. 606/611.

17 Ver art.35 de la ley 5326 de Córdoba.

18 LÓPEZ, Justo, "La estabilidad de los docentes de establecimientos adscriptos", TySS, Año VII, N 4, p. 262.

19 SECO, Docentes privados. Régimen laboral,cit.,p.672 y sgtes.

20 ZUNINO-FANCHÍN, Régimen legal de los docentes privados, cit., p.203/204.
} 
decreto de necesidad y urgencia N³4/2019 que declaró la emergencia pública en materia ocupacional y dispuso la duplicación de las indemnizaciones (doble indemnización) derivadas de los despidos incausados privados que se produzcan durante su vigencia (13/12/2019 al 9/06/2020 inclusive).

El 10 de junio de 2020 el Gobierno extendió el plazo por otros 180 días mediante el DNU №528/2020. Por lo cual la doble indemnización regirá hasta el 7 de diciembre de 2020.

\section{IV.-Tiempos de excepción. Coronavirus y DNU}

1. - - La ley 27.541 (B.O.,23/12/2019) declaró la emergencia pública en materia económica, financiera, fiscal, administrativa, previsional, tarifaria, energética, sanitaria y social.

A la crisis económica, en que se encontraba nuestro país desde tiempo atrás, se le sumó el brote del Coronavirus, que dio lugar a la declaración de pandemia por COVID -19, por parte de la Organización Mundial de la Salud.

En ese marco el gobierno nacional ha dictado un sinnúmero de normas, de diversa jerarquía, con el objeto de salvaguardar el derecho colectivo a la salud pública y los derechos subjetivos esenciales a la vida y a la integridad física.

Entre ellos se halla el DNU $N^{\circ} 297 / 20$ por el que se dispuso el "aislamiento social, preventivo y obligatorio"de la población. Esa inusual medida impactó directamente sobre la actividad económica del país y en el sistema de producción de bienes y servicios y esta situación de emergencia afectó a los trabajadores. Se pretende con ello que no se pierdan puestos de trabajo y evitar que se caiga en el desempleo, que conlleva a la marginalidad de la población.

Además se dictó el decreto de necesidad y urgencia 329/2020 (B.0.,31/03/2020) cuya justificación se expresa en el art. $1^{\circ}$ de él.

2. - Estábamos sin dudas ante una situación de emergencia cuando se dictó el primer DNU citado. Ella puede conceptualizarse a partir de lo expuesto por la CSJN, 27/12/1990, en el caso "Peralta, Luis A. y otro c. Estado nacional (Ministerio de Economía --Banco Central--)"21 diciendo que "abarca un hecho cuyo ámbito temporal difiere según circunstancias modales de épocas y sitios. Se trata de una situación extraordinaria, que gravita sobre el orden económico-social, con su carga de perturbación acumulada, en variables de escasez, pobreza, penuria o indigencia, origina un estado de necesidad al que hay que ponerle fin". Es "una situación de crisis o de necesidad pública" que "exige la adopción de medidas tendientes a salvaguardar los intereses generales situaciones de gravedad perturbación social y económica desastres o graves perturbaciones de carácter físico, económico o de otra índole." Los requisitos para que la legislación de emergencia que sea constitucional según la clásica doctrina de la Corte, expuesta en ese fallo se reúnen: "1) que exista una situación de emergencia que imponga al Estado el deber de amparar los intereses vitales de la comunidad[declarada por una ley del Poder Legislativo]; 2) que la ley tenga como finalidad legítima, la de proteger los intereses generales de la sociedad y no a determinados individuos; 3) que la moratoria sea razonable, acordando un alivio justificado por las circunstancias; 4) que su duración sea temporal y limitada al plazo indispensable para que desaparezcan las causas que hicieron necesaria la moratoria". 
Expresó la CSJN en el caso "Peralta" que a los poderes del Estado les corresponde "proveer todo lo conducente a la prosperidad del país y al bienestar de sus habitantes, lo que significa atender a la conservación del sistema político y del orden económico, sin los cuales no podría subsistir la organización jurídica sobre la que reposan los derechos y garantías individuales. Para que éstas tengan concreta realidad, es esencial la subsistencia del Estado, de su estructura jurídica y su ordenamiento económico y político. Su existencia hace posible el disfrute de los derechos de la libertad y del patrimonio que asegura la Constitución". Según el Preámbulo de la CN se debe tender "a constituir la unión nacional", propósito que permanece vigente para todos los tiempos.

\section{V.-La prohibición de los despidos sin causa y por las causales de falta o disminución de trabajo y fuerza mayor en el DIMU 329/2020 (B.0.,31/03/2020)}

\section{1. - La norma}

Refiere el art. $2^{\circ}$ del DNU original que comentamos:

"Prohíbense los despidos sin justa causa y por las causales de falta o disminución de trabajo y fuerza mayor por el plazo de SESENTA (60) días contados a partir de la fecha de publicación del presente decreto en el Boletín Oficial."

\section{2. -Fundamentos}

En los Considerandos del decreto se expresan los fundamentos que tuvo el Poder Ejecutivo para dictarlo. Expuso que la crisis excepcional conlleva la necesidad de adoptar medidas de idéntica índole.

Agregó que ello se hace en el marco del Pacto Internacional de Derechos Económicos, Sociales y Culturales, con el objetivo de preservar la paz social, para garantizar el derecho de toda persona a tener la oportunidad de ganarse la vida mediante su trabajo que le asegure condiciones de existencia dignas para ella y para su familia.

Insistió en que el art.14 bis de la CN impone una protección específica al trabajo en sus diversas formas y que, en la coyuntura, deviene indispensable la preservación de los puestos de trabajo.

Además dijo que la Organización Internacional del Trabajo, el 23 de marzo de 2020, ha emitido un documento "Las normas de la OlTy el Covid 19 (Coronavirus)" que revela la preocupación mundial y alude a la necesidad de que los gobiernos implementen medidas dirigidas a paliar los efectos nocivos en el mundo del trabajo, en particular en lo referido a la conservación de los puestos de labor $y$, en tal sentido, recuerda la importancia de tener presente la Recomendación 166.

Apuntó que la jurisprudencia de la CSJN expresa que el trabajador es sujeto de preferente tutela constitucional. Por ello entendió "imprescindible habilitar mecanismos que resguarden la seguridad de ingresos de los trabajadores y trabajadoras, aun en la contingencia de no poder prestarservicios, sea en forma presencial o en modos alternativos previamente pactados." Resaltó que resulta indispensable garantizar la conservación de los puestos de trabajo por un plazo razonable, en aras de preservar la paz social.

\section{3. -Nuestro comentario}

a) El despido inmotivado o injustificado o sin expresión de causa o arbitrario o 
ad nutum (los tomaremos como sinónimos), al igual que a los despidos y suspensiones dispuestas con invocación de la fuerza mayor o falta o disminución de trabajo, por medio del DNU, son elevados al estatus jurídico de acto con objeto ilícito 22 (art.279, CCyCom.).

Esa disposición alcanza a todos los trabajadores del país regidos por el Derecho del Trabajo, pasibles de despidos sin expresión de causa y de los fundados en las dos causales de raíz económica, sea que se rijan por la LCT o por los estatutos especiales. La ley no distingue; por ende no debemos distinguir.

Nuestra inicial intuición de que abarcaba a los trabajadores de la construcción, a los agrarios, a los del servicio de casas particulares, a los docentes privados, etc., se ha comprobado casi en su totalidad. Sólo se discute su alcance en la jurisprudencia a los trabajadores del régimen de la construcción, aunque la mayoría lo admite. ${ }^{23}$

Entendimos que la prohibición alcanza también al despido directo sin expresión de causa producido en el periodo de prueba,art.92 bis LCT, porque el DNU no distingue. "Ubi lex non distinguit, nec nos distinguere debemus".

Además sería contradictorio con los objetivos de la norma que es posterior a la del art.92 bis LCT, que el DNU fue dictado en el marco de la emergencia sanitaria (para la conservación de las fuentes de trabajo) y que prevalece sobre la de la normalidad. La literalidad del art.92 bis de la LCT admite el despido sin expresión de causa. En consecuencia, cae dentro de la prohibición del DNU bajo examen.

b) En el caso de los docentes en cargos curriculares, de planta funcional aprobada o programáticos, dependientes de institutos privados reconocidos o adscriptos a la enseñanza oficial, laya amplia protección que tenían se extiende un poco más.

En épocas normales ellos pueden ser objeto de despidos directos sin expresión de causadespido libre pero indemnizado (duplicadas o no según se aplique el DNU aludido).

Pero esa clase de despido no fue lícito en el periodo de 60 días inicial previsto por el DNU 329/2020 (B.0.,31/03/2020), ni en los 60 días más previstos por el DNU 487/2020 (B.O.,19/5/2020).

Tampoco lo es por los 60 días más que ordenó el decreto 624/2020 (B.O.,29/7/2020), contados a partir del vencimiento del plazo establecido por el DNU NM87/20, aunque con algunas nuevas precisiones, que vence el 26 de setiembre de 2020.

c) La prohibición del DNU no alcanza a los despidos directos fundados en justa causa, salvo que la esgrimida sea palmariamente falsa o insuficiente.

Tampoco alcanza a otros tipos de extinción del contrato de trabajo que no sean despidos incausados, por causas económicas o por fuerza mayor.

22 MACHADO, José Daniel, Primer abordaje al DNU 329/2020, Rubinzal Culzoni, Santa Fe, RC D 1506/2020.

23 Ver a favor: Cámara del Trabajo, Cipolletti, Río Negro, 22/05/2020, "Quintana, Rubén Alfredo y otros s/ Medidas cautelares": Trib. Trab. № 2, La Plata, Buenos Aires; 4/8/2020, "Moreno, Darío Ángel vs. Brictom S.A. s. Reinstalación (Sumarísimo); Cámara Única del Trabajo, Sala I, Córdoba, 28/8/2020, "Villarroel, Sebastián Enrique $d$ BOETTO Y BUTIGLIENGO SA. -Medida autosatisfactiva”. Mayoría.

En contra: Juzgado de Conciliación de Segunda Nominación, Río Cuarto, sentencia N ${ }^{\circ}$ 55,8/7/2020, autos: "Arias, Francisco Esteban $d$ Tecma SRL. Medida autosatisfactiva"; Cámara Única del Trabajo, Córdoba, Sala VI, A ${ }^{\circ} N^{\circ} 98,21 / 08 / 2020$, "Maini, Alberto Mauricio $d$ BOETTO Y BUTTIGLIENGO S.A. Medida autosatisfactiva - Cuerpo de apelación" . 
Según el DNU N624(B.0.29/7/2020) la prórroga de la veda no será aplicable a las contrataciones celebradas con posterioridad a su entrada en vigencia (que fue el 29 de julio de 2020, art. $5^{\circ}$ del nuevo DNU).

Además el art. $6^{\circ}$ de ese DNU refiere: "Las prohibiciones previstas en este decreto no serán de aplicación en el ámbito del Sector Público Nacional definido en el artículo $8^{\circ}$ de la Ley $\mathrm{N}^{\circ}$ 24.156 y sus modificatorias, con independencia del régimen jurídico al que se encuentre sujeto el personal de los organismos, sociedades, empresas o entidades que lo integran."

d) El despido directo ¡ncausado o ad nutum o sin expresión de causa es un acto de violencia, de fuerza, brutal.

Se discute en doctrina y jurisprudencia si él es un derecho del empleador o un acto ilícito contractual, con reconocidos sostenedores de ambas posturas.

Empero en este tiempo la mayoría de la doctrina nacional se inclina por la posición- que compartimos- que él implica un acto ilícito contractual. Con él se viola la promesa de dar ocupación hasta que el trabajador esté en condiciones de obtener alguna de las prestaciones previsionales de la ley 24.241 que se efectuara en el contrato, que funciona como regla.

En Argentina se ha optado legislativamente por limitar las indemnizaciones que el empleador le debe al trabajador que es objeto de un despido injustificado estableciendo una tarifa legal. A cambio de esa limitación, el legislador exime al trabajador despedido de la necesidad de demostrar los perjuicios sufridos. Es un claro ejemplo de una ley transaccional. 242526

Fue Justo López, tiempo atrás, quien dijo que una cosa "es que el ordenamiento reconozca aptitud extintiva a la voluntad unilateral del empleadores decir que entre el binomio antitético eficacia/nulidad se incline por la primera)y otra muy distinta es considerarle un acto lícito o un derecho subjetivoß̨p despido incausado en épocas normales es válido pero ilícito.

En el art.14 bis, la CN manda a proteger a los trabajadores contra el despido arbitrario. La Constitución Nacional "no puede proteger 'contra'de otra manera que estableciendo un marco de juridicidad y sus puntos de ruptura que aparecen como lo antijurídico. Por lo tanto aquello contra lo que la Constitución protege (en el caso, el despido arbitrario) es por definición antijurídico, aquello que afecta lo que es designado por el propio texto como dentro del marco de juridicidad. Por lo tanto, para que la norma aplicable al despido arbitrario pueda ser reconocida como perteneciente al sistema constitucional, ella debe proteger contra éste." 16

La CSJN en el caso "Álvarez cJ Cencosud S.A.", 7/12/2010, por ajustada mayoría admitió la reinstalación en el Derecho del Trabajo argentino (cierto que en un caso de despido discriminatorio) superando el cerrado criterio expuesto en el caso "De Lúea cJ Banco Francés" de 1969 para los trabajadores del sector privado, a quienes como regla se reconoce estabilidad impropia.

24 MAZA, Miguel Angel, comentario al art.245, en Ley de contrato de trabajo 20.744 comentada, $3^{*}$ edición actualizada, La Ley, Buenos Aires, 2009 , p.393. 25 LÓPEZ, Justo, Despido arbitrario y estabilidad, LT, XXI-A-291.

26 ARIAS GIBERT, Enrique, "La protección contra el despido arbitrario en el modelo constitucional argentino", en Revista de Derecho Laboral, 2014-1, El Derecho del Trabajo en la Constitución Nacional-1, Rubinzal Culzoni, Santa Fe, 2014,p.400. 
e) El derecho al trabajo, reconocido por variados instrumentos internacionales que conforman el bloque de constitucionalidad federal argentino, implica entre otras cosas, el derecho de no ser privado arbitrariamente del trabajo que se tiene.

La jurisprudencia de la Corte Interamericana de Derechos Humanos, 31 de agosto de 2017, en el caso "Lagos del Campo vs.Perú"27 se refiere al tema estabilidad. De ese modo comienza a abrirse paso en la doctrina latinoamericana, basada en el derecho al trabajo, la idea de que el despido directo debe ser causado. Con ello el sistema de despido libre pero indemnizado, que admiten las normas locales para los trabajadores privados, recibe un serio cuestionamiento a su convencionalidad.

En dicho fallo la $\mathrm{CIDH}$ refiere que "la estabilidad laboral no consiste en una permanencia irrestricta en el puesto de trabajo, sino de respetar este derecho, entre otras medidas, otorgando debidas garantías de protección al trabajador a fin de que, en caso de despido se realice éste bajo causas justificadas, lo cual implica que el empleador acredite las razones suficientes para imponer dicha sanción con las debidas garantías, y frente a ello el trabajador pueda recurrir tal decisión ante las autoridades internas, quienes verifiquen que las causales imputadas no sean arbitrarias o contrarias a derecho."

En otro fallo de la $\mathrm{CIDH}$, 'Trabajadores Cesados de Petroperú y otros vs. Perú", $23 / 11 / 2017,28$ la Corte de San José de Costa Rica consideró que el derecho al trabajo incluye el derecho a garantizar el acceso a la justicia y la tutela judicial efectiva, tanto en el ámbito público como en el ámbito privado de las relaciones laborales."29

f) El derecho a la estabilidad, en tanto medio de subsistencia del trabajador, está conectado necesariamente al derecho a la vida y constituye, por ende, un derecho fundamental del que nadie puede ser privado en forma injusta. ${ }^{30}$

Así lo reconoce la CSJN, interpretando el art.6 $6^{\circ}$ del PIDESC, en tanto "el derecho a trabajar (es) comprensivo del derecho del trabajador a no verse privado arbitrariamente de su empleo" (caso "Vizzoti c/AMSA", 14/09/04, Fallos 327:3677). ${ }^{31}$

El Comité de Derechos Económicos, Sociales y Culturales, en su Observación General No.18 sobre el derecho al trabajo, expresó que este mismo "implica el derecho a no ser privado injustamente del empleo".

El Protocolo Adicional a la Convención Americana sobre Derechos Humanos en Materia de Derechos Económicos, Sociales y Culturales, Ilamado "Protocolo de San Salvador", fue suscripto en San Salvador, República de El Salvador, 17/11/1988, vigente desde el 6 de noviembre de 1999. Fue ratificado por Argentina32, tiene jerarquía supralegal y refiere: "Artículo $7^{\circ}$

\footnotetext{
27 Ver http://www.corteidh.or.cr/docs/casos/articulos/seriec_340_esp.pdf, consultado el 25 de octubre de 2018.

28 Ver http://www.corteidh.or.cr/docs/casos/articulos/resumen_344_esp.pdf, consultada el 25 de octubre de 2018.

29 ARESE, César, “¿Es necesario ratificar el convenio 158 de la Organización Internacional del Trabajo?”, RDL, 2018-1,Contratación laboral y despido-1, Rubinzal Culzoni, Santa Fe, 2018,p,379.

30 MACHADO, ob.cit.

31 GIALDINO, Rolando, El derecho al trabajo en la observación general N ${ }^{\circ} 18$ del Comité de Derechos Económicos, Sociales y Culturales; en RD.L.S.S, Lexis Nexis; 23/2006, p.2085.

32 Aprobado por la República Argentina por ley 24.658 (B.0.5/8/1996). Fue ratificado por el Gobierno argentino el 23/10/2003.
} 
Condiciones Justas, Equitativas y Satisfactorias de Trabajo

Los Estados partes en el presente Protocolo reconocen que el derecho al trabajo al que se refiere el artículo anterior supone que toda persona goce del mismo en condiciones justas, equitativas y satisfactorias, para lo cual dichos Estados garantizarán en sus legislaciones nacionales, de manera particular:

....d. la estabilidad de los trabajadores en sus empleos, de acuerdo con las características de las industrias y profesiones y con las causas de justa separación. En casos de despido injustificado, el trabajador tendrá derecho a una indemnización o a la readmisión en el empleo o a cualesquiera otra prestación prevista por la legislación nacional;;...".

g) El Convenio 158, OIT, sobre la terminación de la relación de trabajo, 1982- que no ha sido aún ratificado por Argentina y que por ello no es obligatorio, en principiosexpresa:

"Sección A. Justificación de la Terminación

Artículo 4

No se pondrá término a la relación de trabajo de un trabajador a menos que exista para ello una causa justificada relacionada con su capacidad o su conducta o basada en las necesidades de funcionamiento de la empresa, establecimiento o servicio."

"Artículo 10

Si los organismos mencionados en el artículo 8 del presente Convenio llegan a la conclusión de que la terminación de la relación de trabajo es injustificada y si en virtud de la legislación y la práctica nacionales no estuvieran facultados o no consideraran posible, dadas las circunstancias, anular la terminación y eventualmente ordenar o proponer la readmisión del trabajador, tendrán la facultad de ordenar el pago de una indemnización adecuada u otra reparación que se considere apropiada."

A tenor de este instrumento internacional el despido debe ser "causado", fundado en causas objetivas o subjetivas, art.4 $4^{\circ}$. Establece la imposibilidad del despido sin causa por mero arbitrio del empleador, es decir que no hay para la OIT la aberrante "libertad de despedir" en términos de Juan Pablo Capón Filas.

Aunque no se haya ratificado, ese Convenio constituye una pauta de interpretación adecuada de la norma relativa a la protección contra el despido arbitrario.

Asilo señaló la CSJN en el precedente "González, Martín Nicolás c/ Polimat S.A."(19/5/2010) y en "Álvarez, Maximiliano y otros c/ Cencosud S.A. s/ acción de amparo"(7/12/2010). Para una postura estricta no forma parte del bloque de juridicidad argentino, pero es al menos una guía respecto de los contenidos de la regulación constitucional o legal.

La CIDH lo aplica en "Lagos del Campo" porque se relaciona con el PIDESC,art.6º

h) Puede concluirse sin hesitar que "los instrumentos internacionales referidos consagran, en forma más o menos explícita, el derecho a la estabilidad en el empleo, aunque ninguno de ellos establece una fórmula única de protección de ese derecho, que 33

33 POMPA, Roberto Carlos, "La estabilidad como derecho humano", en AA. W. RAMíREZ, Luis(Coord.), El Derecho Laboral en la crisis global, B de F, Montevideo-Buenos Aires,2009, p.47, dice lo contrario. 
puede consistir alternativamente, en la reinstalación en el empleo, en una indemnización o en alguna otra prestación".

La misma CSJN expresó en el Considerando 80 del fallo "Madorrán C/A.N.A.",3/5/2007, que el PIDESC "si bien no impone la reinstalación, tampoco la descarta".

Si bien también se admite la posibilidad de una indemnización frente al despido directo incausado (desde la ley 11.729 de 1934 se optó por una indemnización tarifada), la reinstalación de un trabajador así despedido se desprende como posible, consecuencia de un derecho humano fundamental como es el derecho al trabajo. ${ }^{34}$

Concluimos entonces que es constitucional y convencional que durante el periodo en que esté vigente un régimen de estabilidad propia para esos trabajadores- entre ellos los docentes privados de cargos curriculares, de planta funcional o programáticos, dependientes de institutos privados adscriptos a la enseñanza oficial, de quienes nos ocupamos-. No pueden ser despedidos sin expresión de causa. ${ }^{35}$ Tampoco alegando causas económicas ni fuerza mayor.

i) EL DNU ha ido más allá que algunos antecedentes europeos. En el marco de la pandemia por el Coronavirus se han adoptado similares normas y prohibiciones que las que contiene el antecedente criollo. España, Italia y Grecia -con variantes- han prohibido los despidos por causas objetivas, por lo que las empresas no podrán prescindir de sus empleados alegando motivos económicos. Así ha sucedido en España ${ }^{36}$, en Italia ${ }^{37}$ y Grecia 38

j) Durante la veda para los despidos incausados y los otros dispuesta por el DNU aludido y sus prórrogas, el empleador no puede cursar el preaviso, salvo que se especifique que éste que comenzará a correr después del cese de aquélla ${ }^{39}$, arg. art.239,LCT. Es que si no puede lo más tampoco puede lo menos.

\section{VI.- Efectos de los despidos en violación al DNU}

1. - Expresa el art. $4^{\circ}$ del DNU inicial y se repite en sus prórrogas:

"Los despidos y las suspensiones que se dispongan en violación de lo dispuesto en el artículo $2^{\circ}$ y primer párrafo del artículo $3^{\circ}$ del presente decreto, no producirán efecto alguno, manteniéndose vigentes las relaciones laborales existentes y sus condiciones actuales."

2. -De producirse uno de esos actos de objeto ilícito que prevé el DNU la sanción es la ineficacia. El acto será nulo (art.388,CCyCom.). No produce los efectos pretendidos por el empleador, no extingue ni suspende la relación de trabajo (art.390,CCyCom.). Los efectos propios de la nulidad es volver las cosas al estado anterior al acto así considerado. No habrá despido ni suspensión.

\footnotetext{
34 MACHADO, ob.cit.

35 En rigor de verdad también gozarán de estabilidad absoluta o propia pro tempore los docentes extrprogramáticos o extracurriculares o fuera de planta funcional de institutos adscriptos y los docentes de institutos o academias privadas no adscriptas a la enseñanza oficial, al menos por este tiempo.

36 PASCUAL CORTÉS, Raquel https://cincodias.elpais.com/cincodias/2020/03/27/economia/1585300146_319220.html, 27/3/2020, consultada el 4 de abril de 2020.

37 https://www.europapress.es/economia/laboral -00346/noticia-italia-prohíbe despidos 60 dias coronavirus 20200317130902.html del 17/3/2020, consultada el 4 de abril de 2020 .

38 https://www.expansion.com/economia/2020/03/21/5e75f7f8e5fdeab92d8b45f4.html, consultada el 4 de abril de 2020

39 MACHADO, ob.cit.
} 
A nuestro juicio es de nulidad relativa. ${ }^{40}$ Compartimos con De la Fuente que "la invalidez del acto resolutorio constituye una sanción establecida en beneficio especial y particular del trabajador", y representa por lo tanto un caso de "nulidad de protección o relativa/"1"No se encuentra comprometido el orden público sino que existe un interés privado del trabajador, quien debe decidir si le conviene "invalidar el despido o mantener su eficacia, siendo optativa su decisión personal de conservar o no el vínculo contractual."42 Una razón fuerte para afirmar el carácter relativo de la nulidad es que la LCT consagra la prescripción de la acciones (art.256) sin distinción alguna. Por el solo transcurso del tiempo más la inacción del acreedor, el trabajador puede convalidar el despido nulo. ${ }^{43}$

3. $\quad-E l$ afectado por un despido nulo tiene derecho a la reincorporación al puesto de trabajo, reinstalación o readmisión (términos que usa la legislación, jurisprudencia y doctrina para esos casos) porque de hecho no se le permite trabajar.

Además tiene derecho a los salarios caídos que haya dejado de percibir a consecuencia del acto ilícito hasta la efectiva reincorporación. Son efectos propios de la nulidad,art.390, CCyCom.

4. - - Pero también el trabajador despedido tiene disponible la alternativa de demandar las indemnizaciones que corresponda por el despido, con más la duplicación prevista por el DNU 34/2019 si correspondiera (rubros de los arts.232, 233 y 245, LCT), arg. art.52, ley 23.551, y no pedir la reinstalación.

\section{Vil.- Vías para hacer valer los derechos de los trabajadores en la excepción}

a) El trabajador despedido sin causa, en este periodo y respecto de esa clase de despido que no se considera válido, podría utilizar para su reincorporación la vía del amparo del art.43. Constitución Nacional ${ }^{44}$ (ante un derecho líquido y exigióle). No es necesario para ello demasiada prueba.

b) También podría pedirlo por vía medida autosatisfactiva u otra similar. De cualquier modo siempre cabe la posibilidad de un juicio laboral ordinario.

c) La reinstalación podría ser solicitada y ordenada inaudita parte vía medida cautelar porque los recaudos del fumus bonis juris y el periculum in mora, propios de esta clase de medidas, son autoevidentes. 45

d) Asimismo podría el trabajador, ante el incumplimiento de los deberes patronales hacer denuncia del contrato (art.246,LCT), disponer el despido indirecto, previa intimación por dos días hábiles. Esto se basa en la analogía por cuanto sucede con los representantes sindicales.

\section{VIII.-Condusiones}

1.-En tiempo normal los docentes, dependientes de institutos privados reconocidos o adscriptos a la enseñanza oficial, de planta funcional o curriculares

\footnotetext{
40 DE LA FUENTE, ob.cit.

41 ídem.

42 Ibídem.

43 Ibídem.

44 MACHADO, ob.cit.

45 ídem nota anterior.
} 
o programáticos, gozan de estabilidad relativa propia, arts.13 y 14 de la ley 13.047, vinculado al "principio de la equiparación"con los docentes de escuelas de gestión estatal curriculares.

En este tiempo se encuentra tutelada su estabilidad de una mejor manera que la de los trabajadores privados en general debido a la procedimentalización y causalización del despido directo46; pero su protección es menor que la de los docentes de institutos educativos públicos de gestión estatal.

Su estabilidad es relativa porque no se garantiza la reincorporación del trabajador. Se niega eficacia al despido cuando ha sido por causales no previstas por la norma o desestimadas que fueran aquéllas o no se haya cumplido el procedimiento previo(sumario) ante la autoridad administrativa. Cabe allí la reinstalación y salarios caídos.

Pero en esta clase de estabilidad la decisión de reinstalar depende del empleador. Si mantiene la intención derogatoria del contrato deberá pagar la indemnización tarifada más los salarios caídos hasta la reinstalación o hasta la decisión de no hacerlo. ${ }^{47}$

2. -En tiempo de pandemia, el DNU N³29/2020(B.O.,31/3/2020) del Poder Ejecutivo nacional se dictó en el marco de la emergencia sanitaria por el coronavirus y sus prórrogas decididas por el DNU N487/2020 (B.O.,19/5/2020) y el DNU N 624/2020 (B.O.,29/7/2020) prohibieron los despidos sin justa causa y por causas económicas y por fuerza mayor por el plazo de 60 días contados a partir de la fecha de su publicación en el Boletín Oficial, desde el 31 de marzo hasta el 29 de mayo de 2020, luego hasta el 28 de julio y más tarde hasta el 26 de setiembre de 2020, lo que quizás pueda a su vez prorrogarse.

Se ha establecido un régimen de estabilidad propia o absoluta para todos los trabajadores privados a los que alcanzan esos DNU como se anticipó- incluidos los docentes privados de cualquier nivel, curriculares o no- pero pro tempore, porque es limitada al plazo de veda.

Recuérdese la veda que no alcanza a los nuevos contratosa partir del 29 de julio de 2020 según el DNU 624/2020.

3. - La decisión del Poder Ejecutivo Nacional aparece como constitucional y convencional, adecuada a normas supralegales que él mismo cita y a otras ut supra referidas, como a la jurisprudencia de la CSJN y la $\mathrm{CIDH}$.

4. -Aunque por este periodo limitado de tiempo, los docentes de planta funcional o curriculares o programáticos, dependientes de institutos privados adscriptos gozan de una doble protección:

a) Ante el despido directo causado: para que sea legítimo, éste debe adecuarse a las causales previstas y vigentes en el art.13 de la ley 13.047 y procedimentalizado con un sumario previo ante la autoridad administrativa. Hay algunas causales allí no contenidas que no exigen sumario previo pero sí expresión de causa. Esta protección la tienen también en épocas normales. 
Ante el despido incausado y también ante el despido causado injustificado o cuando el empleador no quiera readmitir al trabajador, por el periodo de veda los DNU aludidos les confieren tanto a ellos- como a los demás trabajadores privados- estabilidad absoluta o propia, con los efectos que el DNU prevé y con las consecuencias que su violación implica ya señaladas.

La protección de esta clase de trabajadores se ha intensificado, por ahora por desde el 31 de marzo en adelante. Pero no alcanza a los contratos nuevos desde el 29 de julio de 2020.

5.- La causalidad del despido directo ya está entre nosotros normativamente, por ahora por un tiempo limitado, aunque anticipado por la ley 13.047 para esos docentes privados desde 1947.Se vincula con reciente jurisprudencia internacional que interpreta normas supralegales y supranacionales vigentes para nosotros o no (según como se entienda el Convenio 158 de la OIT).

Pasada la emergencia y la vigencia del DNU, la incógnita está en si se volverá para todos los trabajadores privados en Argentina al sistema de estabilidad relativa impropia o se podrá pasar a una intermedia, como es la que acompaña a los docentes privados mencionados desde 1947, parecida a la que del Estatuto de los Trabajadores español para el caso de despido improcedente, o la excepción del DNU se volverá regla. 